PROCEEDINGS OF THE

AMERICAN MATHEMATICAL SOCIETY

Volume 45, Number 2, August 1974

\title{
THE RANGE OF A VECTOR-VALUED MEASURE
}

\section{KURT HELMES}

ABSTRACT. A short proof is given that the weak closure of the range of a totally nonatomic vector-valued measure is convex.

In [3] I. Tweddle showed that the weak closure of the range of a totally nonatomic vector-measure is convex by proving an extension of a lemma used in [1] to establish a generalization of Liapunov's theorem on the range of an atomless measure. Taking Liapunov's theorem in the finite dimensional case the proof can be shortened. The notation is the same as in [3].

Theorem. Let $E$ be a separated locally convex space, M a $\sigma$-algebra and $m: M \rightarrow E$ a totally nonatomic vector-measure. Then

$$
\overline{\operatorname{rg} m}^{\sigma}=\overline{\operatorname{co}}(\operatorname{rg} m)=\bigcap_{X^{\prime} \in \mathrm{E}^{\prime}} X^{\prime-1}\left(R_{X^{\prime}}\right) .
$$

Here $\operatorname{rg} m=\{m(A) \mid A \in \mathbb{M}\}, R_{X^{\prime}}=\operatorname{rg}\left(X^{\prime} \cdot m\right)$ and

$$
\mathbf{E}^{\prime}=\left\{X^{\prime} \mid X^{\prime}=\left(\begin{array}{c}
x_{1}^{\prime} \\
\cdot \\
\cdot \\
\cdot \\
x_{n}^{\prime}
\end{array}\right), x_{i}^{\prime} \in E^{\prime}, n \in \mathbf{N} \text { arbitrary }\right\} .
$$

Proof (i) $\overline{\mathrm{rg} \mathrm{m}}^{\sigma} \mathrm{C} \overline{\mathrm{co}}(\mathrm{rg} m)$ is obvious [2, II. 3.11].

(ii) $R_{X^{\prime}}$ is convex and compact for all $X^{\prime} \in E^{\prime}[1,3$. Corollary].

Then $D:=\bigcap_{X^{\prime} \in \mathrm{E}^{\prime}} X^{\prime-1}\left(R_{X^{\prime}}\right)$ is convex, closed and contains $\mathrm{rg} m$. Hence $\overline{\mathrm{co}}(\mathrm{rg} m) \subset D$.

(iii) Let $x \notin \overline{\mathrm{rg} m}^{\sigma}$; then there is a $\sigma\left(E, E^{\prime}\right)$-neighbourhood $V$ of the origin such that $(x+V) \cap \operatorname{rg} m=\varnothing$. By definition of $V$ there exists an $\epsilon>0$ and continuous linear functionals $x_{1}^{\prime}, \ldots, x_{n}^{\prime} \in E^{\prime}$ with $V=$ $\epsilon \cdot \bigcap_{1 \leq i \leq n}\left(\left|x_{i}^{\prime}\right|<1\right)$. Let

Received by the editors August 1, 1973.

AMS (MOS) subject classifications (1.970). Primary 28A45.

Key words and phrases. Vector measures, totally nonatomic.

Copyright $\odot$ 1974, American Mathematical Society 


$$
X^{\prime}=\left(\begin{array}{c}
x_{1}^{\prime} \\
\cdot \\
\cdot \\
x_{n}^{\prime}
\end{array}\right)
$$

then $x \notin X^{\prime-1}\left(R_{X^{\prime}}\right)$ and hence $x \notin D$. Q.E.D.

\section{REFERENCES}

1. J. F. C. Kingman and A. P. Robertson, On a theorem of Lyapunov, J. London Math. Soc. 43 (1968), 347-351. MR 37 \#367.

2. A. P. Robertson and W. J. Robertson, Topologische Vektorräume, B. I. Hochschultaschenbücher, Band 164/164a, Bibliographisches Institut, Mannheim, 1967. MR $35 \# 821$.

3. I. Tweddle, The range of a vector-valued measure, Glasgow Math. J. 13 (1972).

INSTITUT FÜR ANGEWANDTE MATHEMATIK UND INFORMATIK, 5300 BONN, WEGE LERSTRASSE 6, FEDERAL REPUBLIC OF GERMANY 